\title{
Acclimation to high temperature during pollen development
}

\author{
Florian Müller ${ }^{1} \cdot$ Ivo Rieu ${ }^{1}$
}

Received: 19 January 2016/ Accepted: 28 March 2016/Published online: 11 April 2016

(c) The Author(s) 2016. This article is published with open access at Springerlink.com

\section{Key message Pollen heat acclimation.}

Abstract As a consequence of global warming, plants have to face more severe and more frequently occurring periods of high temperature stress. While this affects the whole plant, development of the male gametophyte, the pollen, seems to be the most sensitive process. Given the great importance of functioning pollen for the plant life cycle and for agricultural production, it is necessary to understand this sensitivity. While changes in temperature affect different components of all cells and require a cellular response and acclimation, high temperature effects and responses in developing pollen are distinct from vegetative tissues at several points. This could be related to specific physiological characteristics of developing pollen and supporting tissues which make them vulnerable to high temperature, or its derived effects such as ROS accumulation and carbohydrate starvation. But also expression of heat stress-responsive genes shows unique patterns in developing pollen when compared to vegetative tissues that might explain the failure to withstand high temperatures. As an alternative to viewing pollen failure under high temperature as a result of inherent sensitivity of a specific developmental process, we end by discussing whether it might actually be an adaptation.

Communicated by Enrico Schleiff.

A contribution to the special issue 'Pollen development and stress response'.

\section{Ivo Rieu}

I.Rieu@science.ru.nl

1 Department of Molecular Plant Physiology, Institute for Water and Wetland Research, Radboud University, Nijmegen, The Netherlands
Keywords High temperature response - Heat stress . Pollen development $\cdot$ Male fertility $\cdot$ Acclimation . Tapetum

\section{Introduction}

Plants are exposed to an ever-changing biotic and abiotic environment and need to constantly adapt their development and physiology to maintain organismal and cellular homeostasis (also referred to as acclimation). An environmental parameter that is highly variable, over various time scales, is ambient temperature. High temperatures reached during the day can pose various problems for cellular functioning and strongly affect plant fitness in the longer term. As a consequence of global warming, hot days and heat waves are predicted to increase both in frequency and in intensity in many temperate regions in the coming decades (IPCC 2014). Given the almost complete dependency of humans on agricultural output for food, understanding the reaction of plants to high temperature stress is of great societal importance. While the majority of studies on this subject have focussed on the vegetative (sporophytic) stage of plant growth, the development and functioning of the male gametophyte, or pollen, are known to be among the most temperature-sensitive processes within the plant life cycle (Zinn et al. 2010). Importantly, heatinduced pollen defect is associated with reductions in seed and fruit set. In this review, we will specifically discuss the high temperature sensitivity and acclimation response of developing pollen and see how this compares to that of vegetative tissues. We will also speculate whether previous experience of high temperature by a plant may induce higher tolerance of pollen towards subsequent temperature increases, i.e. leads to acquired thermotolerance, either 
within an individual or in the offspring, and discuss ways in which pollen thermotolerance may be enhanced.

\section{The effect of heat on pollen}

\section{Pollen development}

Pollen, the mature male gametophyte (microgametophyte), is a highly specialized cell type that develops within the anthers of the flower through a complex series of processes. This has been reviewed extensively (Borg et al. 2009). During anther development, the reproductive or sporogenous cells, located centrally within the anther, give rise to the pollen mother cells (PMCs; microsporocytes), while the surrounding non-reproductive cells form sporophytic epidermal, cortical and tapetal cell layers. Pollen development from PMCs can be divided into microsporogenesis and microgametogenesis. During microsporogenesis, PMCs undergo a meiotic division, with the four haploid products (spores) of each meiocyte initially staying together in the form of a tetrad. These tetrads are enclosed by a thick wall, mainly consisting of callose, and surrounded by the locular fluid inside the anther locules. The innermost cell layer of the locule differentiates as the tapetum, a tissue that is essential for microsporogenesis through secreting nutrients, carbohydrates, cell wall components and enzymes into the locular fluid. Among these are callases that digest the callose walls of the tetrads, which then release the unicellular microspores. During subsequent microgametogenesis, the microspores undergo vacuolization, expansion and a mitotic, asymmetric division, resulting in the formation of binuclear pollen grains, harbouring a larger vegetative and smaller generative cell. At this stage, the tapetum undergoes programmed cell death. Pollen will then maturate and desiccate. In the case of tri-nucleate pollen, a second mitotic division of the generative cell into two sperm cells occurs before desiccation, while in binucelate pollen grains this happens after pollen germination.

\section{Heat-induced pollen defects}

Developing microspores and pollen have been known for a long time to be the cells that are most affected by the occurrence of high ambient temperatures (Iwahori 1965). Both short-term high and long-term mildly elevated day and night temperatures negatively affect pollen development. An important question is what the primary heat-induced developmental defect(s) during pollen development are and how this differs between heat profiles.

The earliest heat-induced developmental defects occur during meiosis. Next to increased frequency of crossing over and homologous recombination (Boyko et al. 2005;
Francis et al. 2007; Lebel et al. 1993), chromosome behaviour and meiotic cell division may be affected, leading to unbalanced chromosome separation between spores and formation of diploid dyads (Omidi et al. 2014; Pecrix et al. 2011; Rezaei et al. 2010). In the study of Pecrix et al. (2011), closer investigation revealed that the behaviour of chromosomes during cell division was due to aberrant spindle orientation. High temperatures are known to affect microtubules and cytoskeleton dynamics, which has been studied in vegetative tissues, as well as during pollen tube growth (Muller et al. 2007; Parrotta et al. 2016; Smertenko et al. 1997). While this requires temperatures of above $40{ }^{\circ} \mathrm{C}$ in vegetative cells in Arabidopsis or tobacco, growing pollen tubes are more sensitive $\left(35^{\circ} \mathrm{C}, 3 \mathrm{~h}\right)$ and damage increases with increasing temperature (Parrotta et al. 2016). In agreement with this, aberrant behaviour of chromosomes during meiosis seems to occur especially under more severe heat stress (De Storme and Geelen 2014).

Defects in microsporogenesis have been described in a number of species, both under extreme heat and long-term mild heat profiles (Ahmed et al. 1992; Endo et al. 2009; Kim et al. 2001; Sato et al. 2002). It has been suggested that a reduction in pollen number and viability might be the indirect result of defects in the supportive tapetal cells (De Storme and Geelen 2014; Parish et al. 2012). Aberrations in the timing of tapetum development and degeneration, including hypertrophy and premature as well as delayed degeneration, and morphology of tapetal endoplasmic reticulum have been observed (Abiko et al. 2005; Ahmed et al. 1992; Endo et al. 2009; Harsant et al. 2013; Iwahori 1965; Oshino et al. 2007; Saini et al. 1984; Suzuki et al. 2001). Similar tapetal defects are known from cold and drought stress and occur in different plant species, both monocots like wheat, barley, Brachypodium distachyon and rice, and dicots like cowpea (Vigna unguiculata), snap bean (Phaseolus vulgaris), Arabidopsis and tomato, always associated with reduced pollen viability (De Storme and Geelen 2014; Parish et al. 2012).

Finally, the amount of starch and sugars in maturing pollen grains has been shown to be affected by long-term, mildly elevated temperature. In pollen of bell pepper and tomato, starch has been shown to accumulate during development and reach a maximum after the first pollen mitosis, a few days before flower anthesis. Subsequently, the starch content is reduced again and the concentration of soluble sugars increases (Aloni et al. 2001; Pressman et al. 2002). When grown under continuous mild heat $\left(32^{\circ} \mathrm{C} /\right.$ $26{ }^{\circ} \mathrm{C}$ day/night), the transient accumulation of starch, as well as the final accumulation of soluble sugars, was reduced in developing tomato pollen, correlating with reduced pollen viability, and tomato cultivars with higher pollen thermotolerance were able to maintain higher starch and sugar levels than heat-sensitive lines (Firon et al. 2006; 
Pressman et al. 2002). It could be speculated that high temperatures lead to depletion of these reserves due to increased respiration to sustain adaptive metabolic activity in developing pollen. Alternatively, the carbohydrate-related defects may be the result of decreased hexose supply by the tapetum or due to developmental aberrations during earlier microsporogenesis.

How heat affects the above developmental processes remains to be determined. Studies in vegetative cells have identified several cellular effects of high temperature, including increased membrane fluidity, misfolding of proteins, changes in the specificity and kinetics of enzyme reactions and accumulation of reactive oxygen species (ROS) (Alfonso et al. 2001; Atkin and Tjoelker 2003; Sangwan et al. 2002).

\section{Heat responses during pollen development}

To cope with the various effects of high temperatures and to maintain cellular homeostasis, plants have a sophisticated heat stress response. While this is well studied in vegetative stages of different plant species, especially using Arabidopsis seedlings and tomato cell cultures (Kotak et al. 2007; Scharf et al. 2012), little is known about these mechanisms in developing pollen. Transcriptomic studies of developing Arabidopsis and maize (Zea mays) pollen have shown that, in comparison with vegetative and other generative tissues, developing pollen is a relatively unique cell type (Becker et al. 2003; Davidson et al. 2011). This means that knowledge obtained from vegetative stages is not necessarily applicable to developing pollen and argues for performance of pollen-specific studies.

\section{Heat sensing}

Heat stress leads to broad transcriptomic changes in plants. Genes differentially expressed under high temperatures include heat stress transcription factors (HSFs) and heat shock proteins (HSPs), but they only a account for small proportion of total transcriptomic changes. Transcriptomic studies in wheat and Arabidopsis showed that 5-10\% of all transcripts were differentially expressed under short heat stress, including genes that putatively encode proteins and transcription factors involved in phosphorylation, hormone biosynthesis and signalling, calcium, sugar and lipid signalling pathways, regulation of transcription and translation, primary and secondary metabolism and responses to different biotic and abiotic stresses (Larkindale and Vierling 2008; Mittler et al. 2012; Qin et al. 2008). Prior to these transcriptomic adjustments, plants have to sense changes in temperatures. Four systems have been described that can sense temperature changes and are thought integrate these to induce heat-responsive gene expression (Mittler et al. 2012). An increase in membrane fluidity is among the first consequences of increasing temperatures, and a calcium channel located in the plasma membrane is considered to be the main sensor. Activated by increasing temperatures, it leads to the accumulation of $\mathrm{Ca}^{2+}$ in the cytoplasm and the expression of heat-induced genes, for example by feeding into the HSF pathway as discussed later (Balogh et al. 2013; Mittler et al. 2012). Second, proteins that unfold due to increasing temperatures are sensed by the cytoplasmic and ER unfolded protein response (UPR) and serve as a thermosensor (Moreno and Orellana 2011). The UPR in the cytoplasm involves HSFA2, a major regulator of the HSR, and certain splice variants of HSFA2. In the endoplasmic reticulum, the presence of unfolded proteins leads to the release of bZip transcription factors that enter the nucleus and lead to the expression of heat stress-responsive genes as well (Che et al. 2010). Thirdly, the early accumulation of reactive oxygen species (ROS) is considered one of the first steps in the heat stress signalling cascades. While ROS are constantly produced under normal conditions, especially in mitochondria, chloroplasts and peroxisomes, and directly detoxified by different pathways within these organelles or their vicinity, under high temperatures the balance between production and detoxification seems to be disturbed, leading to the accumulation of ROS (Sharma et al. 2012). And last, a specific histone variant, H2A.Z that is incorporated into nucleosomes especially around the transcriptional start site of genes, seems to regulate nucleosome occupancy at this position in a temperature-sensitive manner (Kumar and Wigge 2010). In a model proposed by Kumar and Wigge (2010), the occupancy of H2A.Z containing nucleosomes declines with increasing temperatures allowing the progression of the polymerase II and transcriptional regulators to access gene-specific regulatory cis-elements, normally occluded by nucleosomes.

It seems likely that the same systems act in developing pollen. Indeed, recently, a calcium channel has been determined to be important for thermotolerance (cycling between $40{ }^{\circ} \mathrm{C}$ day and $-1{ }^{\circ} \mathrm{C}$ night temperature) of Arabidopsis pollen (Tunc-Ozdemir et al. 2013). Mutant plants showed no defects under control conditions, but were more sensitive to high temperature stress and failed to induce expression of heat-responsive transcription factors. Also, accumulation of ROS in pollen upon a short heat shock $\left(42{ }^{\circ} \mathrm{C}, 2 \mathrm{~h}\right.$ ) has been reported (Kumar et al. 2014), and this may play a role in acclimation.

\section{Heat stress transcription factors}

Central to the HSR is a network of heat shock transcription factors (HSF) that can bind a specific palindromic DNA 
sequence, the heat shock element (HSE), and induce the expression of heat-responsive genes (for review Kotak et al. 2007; Scharf et al. 2012). Tomato, for example, possesses 27 different HSFs that can be divided into three different clades (Scharf et al. 2012). These contain different motifs, among which a DNA-binding domain to recognize HSE and an oligomerization domain to form heterooligomers. The division into three different clades is based on structural differences in this oligomerization domain. Under normal temperature conditions, HSFA1, the master regulator of the HSR is located in the cytoplasm and kept inactive by interaction with HSP70 and HSP90 (Hahn et al. 2011). Upon high temperature stress, HSFA1 is activated and together with HSFB1, another HSF that rapidly accumulates under HT and acts as co-activator induces the expression of heat-responsive genes that help to maintain cellular homeostasis and different HSFs that further amplify the HSR (Liu et al. 2011). Among these heat-induced HSFs is HSFA2, which, by oligomerization with HSFA1, forms a so-called superactivator complex that amplifies the HSR (Chan-Schaminet et al. 2009).

High temperature-induced expression of different HSFs has been reported in developing pollen of different species. HSFA 2 and HSFA 3 are upregulated in tomato microspores, and HSFA2 and HSFB1 are also upregulated in developing pollen of Arabidopsis under a short heat shock (Frank et al. 2009; Giorno et al. 2010; Tunc-Ozdemir et al. 2013). Similar to what was found for vegetative tissue, HSFA2 suppression reduced the tolerance of tomato pollen towards a short high temperature stress $\left(39^{\circ} \mathrm{C}, 3 \mathrm{~h}\right)$ during the stages of meiosis and early microspore formation (Fragkostefanakis et al. 2016). On the other hand, HSF function also seems to diverge between leaf and anther to some extent, because a considerable difference in the heatinduced genes was found between leaf and anther, as well as in the set of HSFA2-dependent genes (Fragkostefanakis et al. 2016). And, while in vegetative stages of tomato, HSFA2 is solely expressed under high temperature conditions, HSFA2 transcripts are already abundant under control conditions in young developmental stages of tomato pollen (Fragkostefanakis et al. 2016; Frank et al. 2009; Giorno et al. 2010); thus, HSFs might play an additional, developmental role in pollen development. The same expression pattern is found for AtRen1, an HSFA5-like gene that is important for pollen development. Knockout of Ren1 leads to abnormal pollen development, as well as to higher temperature sensitivity of developing pollen (Renak et al. 2014). Since nucleolar appearance was different, the authors concluded that Ren1 might be related to RNA biogenesis. HSFA5, the closest homologue of Ren1, is also upregulated in developing pollen of Arabidopsis and soy bean, but at later stages than Ren1 (Haerizadeh et al. 2009; Renak et al. 2014). In a tomato protoplast system, HSFA5 was found to inhibit the function of HSFA4, a positive regulator of the HSR also expressed in developing pollen (von Koskull-Doring et al. 2007). Taken together, from the few HSFs that have been studied in pollen under high temperatures, it seems that most of them are induced in response to high temperature like in vegetative tissues, suggesting that HSFs play a similar, major role in the heat response in pollen. Additional functional genomic studies are needed to test this hypothesis.

\section{Heat shock proteins}

Protecting and stabilizing proteins in their native conformation are one of the most important aspects for cells to survive high temperatures stress. This is carried out by high-molecular-weight chaperones called heat shock proteins (HSPs). Especially under high temperature, cells accumulate massive amounts of these proteins to prevent irreversible high temperature damage (Vierling 1991). HSPs are divided into classes according to their molecular weight in kDa (HSP100, HSP90, HSP70, HSP60, HSP40 and small HSP with low molecular weights) and stabilize unfolding proteins, prevent the formation of aggregates, resolubilize aggregated proteins and return them to their native conformation (Hartl et al. 2011; Kotak et al. 2007; Vierling 1991). Low-molecular-weight HSPs also play roles in maintaining the cell membrane integrity (Tsvetkova et al. 2002).

In young developmental stages of tomato pollen, several small HSPs and HSP70 are abundant, suggesting a developmentally controlled process that might help to prepare the cells for environmental stresses ("developmental stress priming"; Chaturvedi et al. (2013); Gagliardi et al. (1995); Volkov et al. (2005)). This fits with the finding that HSFA2 is expressed and activates some of its targets in young anthers under non-stress conditions (Fragkostefanakis et al. 2016; Giorno et al. 2010). Furthermore, HSPs and small HSPs are induced in pollen after a short intense high temperature stress (Chaturvedi et al. 2015; Frank et al. 2009; Kumar et al. 2014). However, this might not apply to all HSPs typically expressed in vegetative stages: studies in different species have shown that in developing, mature and germinating pollen, certain heat-responsive proteins, like HSP100, HSP70 and small HSPs, accumulate less under high temperatures than in vegetative tissue (Cooper et al. 1984; Dupuis and Dumas 1990; Gagliardi et al. 1995; Volkov et al. 2005). A recent study in tomato comes to a similar conclusion, namely that HSFA2, HSP100 and HSP17 are upregulated in developing pollen in response to a short heat stress $\left(39^{\circ} \mathrm{C}, 3 \mathrm{~h}\right)$, but to a considerably lesser extent than in vegetative tissues (Fragkostefanakis et al. 2016). Similarly, promotor-GUS fusions have shown that in response to high temperatures the promotor of a small 
HSP from soy bean is active in all vegetative tissues of Arabidopsis, but not in developing pollen (Crone et al. 2001). The failure of developing pollen to express certain HSP has long been thought to be responsible the high temperature sensitivity of pollen (Frova et al. 1989), and indeed, transgenic overexpression of HSP100, which is not detectable in wild-type pollen of tobacco and cotton under high temperatures, resulted in higher pollen thermotolerance when receiving a short heat stress $\left(46{ }^{\circ} \mathrm{C}, 3 \mathrm{~h}\right.$ or $50{ }^{\circ} \mathrm{C}, 7 \mathrm{~min}$ ) during germination and higher bolt and seed production in greenhouse and field trials (Burke and Chen 2015). Recent microarray studies seem to deliver contrasting results, though detecting transcripts of small HSPs, HSP70 and HSP80 and related DNAJ proteins in pollen under short heat stress (Bita et al. 2011; Endo et al. 2009; Zhang et al. 2014). However, these studies used whole anthers or panicles, contributing a significant amount of vegetative tissues that might mask the unique response of developing pollen. Apart from the common HSPs, other putative chaperones have been detected in developing pollen under heat stress (Cooper et al. 1984; Hopf et al. 1992), as well as proteins with chaperone-related functions. Recent studies have shown that members of the BAG family, involved in recruiting HSPs to client proteins, are expressed in developing tomato pollen under heat stress and might be under control of HSFA2 in vegetative tissues in tomato (Fragkostefanakis et al. 2015; Frank et al. 2009; Giorno et al. 2010). Studies in Arabidopsis have shown that these genes are involved in thermotolerance and overexpression resulted in higher tolerance to a variety of other abiotic stresses, too (Doukhanina et al. 2006).

Thus, in agreement with the findings on HSF expression, pollen seems to be able to mount a classical heat stress response regarding the activation of many HSPs, but it is different from that in vegetative tissue.

\section{Reactive oxygen species}

Mitochondria, chloroplasts and peroxisomes are of great importance for energy-related metabolism in plant cells. However, along with the ordinary reactions, these cellular compartments also produce reactive oxygen species (ROS) that are cytotoxic and are detoxified by a specialized cellular machinery (Sharma et al. 2012). While ROS production and scavenging are well balanced under normal conditions, preventing damages to cellular components, abiotic stresses are well known to greatly increase ROS production and disturb this balance (Bhattacharjee 2013; Foyer and Noctor 2005; Vacca et al. 2004). In vegetative tissues of different plant species, ROS scavenging enzymes and antioxidants are known to be highly induced under high temperatures and contribute to plant thermotolerance (Chao et al. 2009; Mittal et al. 2012; Sairam et al. 2000).
Increasing antioxidant activity has been shown to increase vegetative thermotolerance in different plant species (Almeselmani et al. 2006; Chen et al. 2013; Rui et al. 1990; Sairam et al. 2000; Sengupta et al. 1993; Wu et al. 2012) and might also be of importance for developing pollen. Pollen and tapetum cells are known to accumulate great numbers of mitochondria, twenty times more than in vegetative tissue, and show fast respiration during development and pollen tube growth (Lee and Warmke 1979; Selinski and Scheibe 2014). Under high temperatures, this great amount of mitochondria might lead to a dramatic increase in ROS, stressing the capacities of the ROS scavenging machinery. The only study into this, performed in wheat, indeed shows that pollen hydrogen peroxide level increases dramatically upon a short heat treatment $\left(42{ }^{\circ} \mathrm{C}\right.$, $2 \mathrm{~h}$ ), together with antioxidant capacity (Kumar et al. 2014). A proteomic as well as transcriptomic studies have shown that an ascorbate peroxidase is upregulated in developing tomato and wheat pollen in response to a short heat treatment (Chaturvedi et al. 2015; Frank et al. 2009; Kumar et al. 2014). Also in rice, a number of ROS-related genes were shown to be heat responsive (Zhang et al. 2014), although the use of whole panicles prevents drawing conclusions on developing pollen, specifically. When subjected to high temperatures, plants also accumulate antioxidant substances, like flavonoids, that can scavenge and detoxify ROS (Wahid et al. 2007). Accumulation of these antioxidants during pollen development is essential for pollen germination and pollen tube growth (Coberly and Rausher 2003; Derksen et al. 1999; Schijlen et al. 2007). In response to a short heat stress, pollen accumulates even higher levels of ascorbate and phenolic compounds, like flavonoids, that might imply a role in the high temperature response (Kumar et al. 2014).

\section{Hormones}

Various plant hormones have been linked to heat stress signalling and pollen heat acclimation (Bokszczanin et al. 2013; Mittler et al. 2012). Transcripts related to ethylene signalling are higher expressed after a short heat stress in developing tomato pollen (Frank et al. 2009). Supporting a role of ethylene in acclimation of tomato pollen to heat, pollen of an ethylene insensitive tomato mutant was shown to be more sensitive chronic mild heat stress $\left(32 / 26{ }^{\circ} \mathrm{C}\right.$, day/night), which was associated with reduced accumulation of sucrose in the mature stage (Firon et al. 2012). Additionally, chemical induction of ethylene production prior to a short heat stress $\left(50{ }^{\circ} \mathrm{C}, 2 \mathrm{~h}\right)$ treatment improved pollen thermotolerance, while application of an ethylene inhibitor reduced it (Firon et al. 2012). Auxin synthesis in anthers of Arabidopsis and barley is reduced upon high temperatures, in contrast to the response in vegetative 
tissue. This reduction does not seem to be an acclimation response for pollen per se, though, but rather a defect, as exogenous application of auxin improved pollen thermotolerance to continuous mild heat stress in barley $\left(30{ }^{\circ} \mathrm{C} /\right.$ $25{ }^{\circ} \mathrm{C}$, day/night) and Arabidopsis $\left(31-33^{\circ} \mathrm{C}\right.$ ) (Higashitani 2013; Sakata et al. 2010). Similarly, a microarray study in rice found that among tapetum-specific genes that were downregulated under continuous mild heat stress $\left(39^{\circ} \mathrm{C} /\right.$ $30{ }^{\circ} \mathrm{C}$, day/night) several were related to GA signalling (Endo et al. 2009) and a wheat GA hyposensitive mutant was shown to be hypersensitive to long-term high temperature treatments regarding seed set (Alghabari et al. 2014), while a higher GA content correlated with a higher pollen viability under continuous mild heat stress in rice (Tang et al. 2008). Reduced GA signalling may thus be considered a defect, too. Notably, it could be related to developmental defects observed under heat, as a GA insensitive mutant was shown to have abnormal tapetal development, showing delayed or inhibited programmed cell death and pollen developmental arrest at the microspore stage (Aya et al. 2009; Tsuji et al. 2006). Abscisic acid (ABA) is another plant hormone involved in vegetative thermotolerance (Baron et al. 2012; Larkindale and Huang 2005). However, ABA accumulation seems to negatively affect pollen development (Ji et al. 2011; Parish et al. 2013). In rice florets, exposed to reoccurring heat stress for five days, ABA concentrations were higher than under control conditions, but ABA concentrations have not been measured in pollen itself (Tang et al. 2008). Thus, it seems that ABA accumulation could be a consequence of heat stress with adverse effects on pollen. However, evidence is still scarce and further studies that specifically analyse ABA content in anther tissues are needed to shed light on its role in pollen heat stress effects and response.

\section{Sugar metabolism}

The effect of heat stress on pollen characteristics is associated with changes in carbohydrate metabolism and content in the developing anthers, but there are species-specific effects. In reproductive organs of rice, sugar transporters have been shown to be more active under continuous mild heat, resulting in higher starch levels of mature pollen (Chung et al. 2014). Also in bell pepper, mild heat stress was reported to result in higher starch levels in maturing pollen (Aloni et al. 2001). By contrast, in tomato, continuous mild heat stress was found to cause a reduction in cell wall-bound acid invertase activity in whole anthers of flower buds five days before anthesis, which correlated with reduced starch accumulation two days later (Pressman et al. 2006). Acid invertase catalyses hydrolysis of sucrose, which normally accumulates at the final stage of pollen development. The same reaction may be performed by sucrose synthase, and activity of this enzyme, too, has been reported to be negatively affected by high temperature (> 40/25 ${ }^{\circ} \mathrm{C}$; day/night) in anthers (Kaur et al. 2015). After sucrose is hydrolysed by acid invertase or sucrose synthase, glucose and fructose must be further metabolized. Fructokinase activity, the first step in metabolizing fructose, in bell pepper pollen was also reduced under high temperatures, while hexokinase activity was low and did not show any changes in response to temperature (Karni and Aloni 2002). Interestingly, under higher atmospheric levels of $\mathrm{CO}_{2}$, both enzymes showed increased activity and pollen germination potential under high temperatures was improved (Aloni et al. 2001; Karni and Aloni 2002). Following the phosphorylation, hexoses are further metabolized in glycolysis. Genes related to glycolysis are expressed in tapetal cells and developing pollen, and knockout of these genes results in male sterility, accompanied by defects in tapetal development (Munoz-Bertomeu et al. 2010). Whether changes in sugar and starch levels in developing pollen are an adverse consequence of high temperature (via effects on gene expression or enzyme structure/activity) or the result of active adjustments of the primary metabolism as part of the pollen heat response is currently unclear.

\section{Acquired thermotolerance of pollen development}

While plants possess the ability to withstand a sudden heat shock, they have been shown to be more tolerant to a gradual increase in temperature over time that allows them to acclimate. Similarly, plants are able to survive an otherwise lethal heat stress when preceded by a sub-lethal high temperature treatment. This phenomenon is known as acquired thermotolerance (ATT) and has been studied extensively in vegetative tissues. Various genes and signalling pathways have been described that are necessary for ATT; among these are HSFs and HSPs, different plant hormones, ROS and other signals like miRNA398 (Bokszczanin et al. 2013; Guan et al. 2013; Larkindale and Vierling 2008; Scharf et al. 2012). It is thought that upon a sub-lethal high temperature treatment a set of stress signalling and defensive proteins are produced by the plant and remain present in the cell for some time beyond the initial stress period. Then, upon a second heat stress, protective proteins are already available, while the pre-formed signalling components enable the plant to induce transcription of heat-responsive genes faster and at higher levels. As an alternative mechanism, the faster gene expression response has been suggested to depend on histone H3K4 hyper-methylation (Lamke et al. 2015). Among the HSFs and HSPs, some play a very prominent role in ATT; especially, HSFA2 seems to be a major regulator of 
ATT in Arabidopsis and HSP100 one of the major working horses as knockouts of each of these genes will result in greatly reduced ATT (Hong and Vierling 2000; Schramm et al. 2006; Yang et al. 2006). In vegetative tissues, ethylene signalling has also been related to ATT (Larkindale and Vierling 2008).

While the effect of ATT is described to last for hours up to a few days, there are a few examples that imply that plants might be able to acquire thermotolerance also over longer periods (Charng et al. 2007). In wheat, plants that received two high temperature treatments at earlier developmental stages were performing better when subjected to high temperatures several weeks later, after anthesis (Wang et al. 2011, 2012). In these studies, the authors measured photosynthetic activity of the flag leaf, starch mobilization from the stem and accumulation in the grains. All of them were less affected by high temperatures when plants received acclimation treatments before anthesis.

There is some evidence to suggest that a similar type of ATT also occurs in pollen. Late stages of tomato pollen are able to acquire thermotolerance against a short high temperature stress, and this seems to be dependent on ethylene signalling (Firon et al. 2012). Application of an ethylene inhibitor affected the ability of pollen to acquire thermotolerance and chemical induction of ethylene, prior to a high temperature treatment, increased pollen thermotolerance (Firon et al. 2012). Also, the offspring of Arabidopsis plants grown under continuous mild heat stress for two subsequent generations and one generation at control conditions produced significantly more seeds under continuous mild heat than plants grown under control conditions for three generations prior to the stress (Whittle et al. 2009). Unfortunately, pollen quality was not tested in this study, so it remains unclear whether the increased seed set under high temperatures correlated with increased pollen thermotolerance.

\section{Conclusions and future perspectives}

While the first detailed studies of pollen development under high temperature date back half a century (Iwahori 1965), the reason for the hypersensitivity of pollen to heat relative to vegetative tissue still remains elusive. We have provided an overview of effects heat on pollen and highlighted differences between the heat stress response of pollen and vegetative tissues. From this, it seems that various factors could contribute to high temperature sensitivity (Fig. 1). One possible explanation could be that pollen is not able to mount a proper HSR. HSFs and HSPs are essential for the heat stress response, and perturbation of this stress defence pathway greatly impairs thermotolerance (Mishra et al. 2002; Schramm et al. 2006). The major HSFs and most HSPs seem to be normally heat responsive in pollen, but several typical HSPs (HSP100 and certain small HSPs) accumulate less in developing pollen than in vegetative tissue under high temperature. Thus, this may hamper the full protection against unfolding of proteins. Support comes from the finding that transgenic expression of Arabidopsis HSP100 in cotton and tobacco improved pollen thermotolerance (Burke and Chen 2015). So, why would a microspore have a weak HSR? It could be speculated that a cell that needs to go through a comp series of developmental steps in a very defined/short period time has limited opportunity to respond to environmental influences. In other words, a strong heat response could be expected to severely affect developmental progression of a microspore, which it might not be able to recover from. Developmental priming has been proposed to compensate for a weak HSR, but it is experimentally difficult to separate heat-independent and heat-dependent protective gene expression, which would be required for testing this hypothesis. Alternatively, specific physiological characteristics of pollen and tapetum might be related to temperature sensitivity. Pollen and tapetum seem to have an unusually strong demand for energy, as indicated by the high number of mitochondria in these cells. Differences in starch and sugar accumulation are usually observed under mild continuous heat conditions. Depletion in energy reserves might thus affect tapetum and pollen more than other cells. Several authors have suggested that problems with sugar metabolism constitute the primary heat defect causing pollen failure, but proper experimental testing is urgently needed to clarify whether this is the case, or whether it is merely the consequence of preceding developmental deviations. From the available literature, it seems that at least pollen induces ROS scavengers upon high temperatures and accumulates compounds that act as antioxidants. However, given the great number of mitochondria in pollen and tapetum, it is tempting to speculate that upon heat, these produce a disproportionate amount of ROS that cannot be counteracted by the detoxifying machinery. Measuring ROS at cell level has proved difficult, explaining the gap in knowledge regarding pollen and tapetum. There might be an opportunity to use genetically encoded biosensors to this end, which may even be evaluated in histological sections (Fujikawa et al. 2016; Meyer et al. 2007). Interestingly, high temperature defects in developing pollen and tapetum share some similarities with plants showing cytoplasmic male sterility (CMS), a phenomenon not completely understood yet, but thought to be linked to mitochondrial function and ROS activity $(\mathrm{Hu}$ et al. 2014). About half of the described CMS phenotypes are sensitive to temperatures, and all of them are limited to the development of the male gametophyte. Like under high temperature, aberrations in tapetum development, such as 


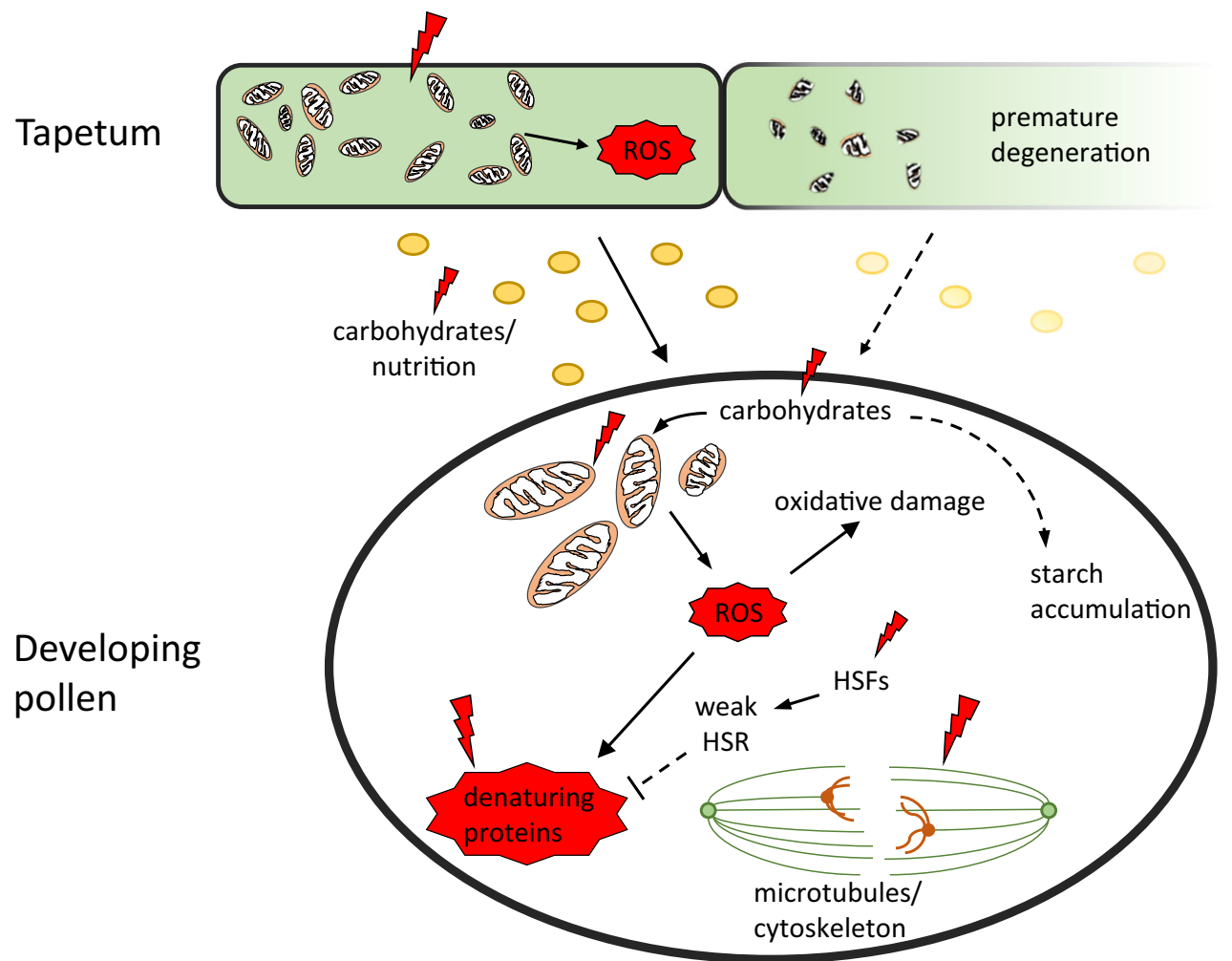

Fig. 1 Possible defects related to pollen failure under heat. Developing pollen and the surrounding tapetal cells show a high sensitivity to heat stress (lightning symbol) that often results in premature degeneration of tapetal cells and aberrant developmental or programmed cell death of developing pollen. While the cause of this sensitivity remains unknown, we suggest several physiological characteristics of developing pollen that might be related to pollen failure under heat. Firstly, developing pollen and tapetal cells contain high numbers of mitochondria. Therefore, increased respiration as adaptation to heat might result in the production of a disproportional amount of reactive oxygen species (ROS) that cannot be sufficiently detoxified by the protective cellular mechanisms, causing damages to different cellular components. Secondly, premature tapetum degeneration or effects on specific metabolic enzymes under heat stress

hypertrophy or delayed and inhibited PCD, are observed in CMS plants (Holford et al. 1991; Liu et al. 2009; Schnable and Wise 1998; Smith et al. 2002). This phenotype also closely resembles that of signalling mutants in the GA pathway, which might be involved in pollen thermotolerance (Chhun et al. 2007; Jacobsen and Olszewski 1991; Koornneef and van der Veen 1980; Tang et al. 2008). Whether these similarities are a coincidence or if there is a mechanistic relation in triggering pollen defects remains to be seen.

Taken together, both the development of pollen and tapetum and the high temperature response of developing pollen show some unique characteristics that might explain the high temperature sensitivity of pollen. A contrasting as yet unexplored alternative explanation could be that pollen heat sensitivity is in fact an adaptation by itself. Firstly, might result in reduced delivery of carbohydrates and other compounds necessary for normal pollen development. Together, the reduced availability of carbohydrates and the increased respiration with a high number of mitochondria might lead to the depletion of energy reserves and defects during subsequent development. Thirdly, heat results in the unfolding of proteins. This effect is normally mitigated by the classical chaperone heat stress response (HSR). In pollen, heat activates HSFs, important signalling components of the HSR; however, the cell fails to mount a full HSR comparable to vegetative tissues, which is then insufficient to protect and refold proteins. Finally, microtubules and the cytoskeleton are known to be sensitive to ROS and heat stress. During the meiotic cell division, heat affects the orientation of the spindle apparatus leading aberrant chromosome behaviour and subsequent failure of pollen development

because the subsequent processes of embryo and fruit development are adversely affected by high temperature (Bac-Molenaar et al. 2015; Mulholland et al. 2003), preventing investment in reproduction at too high temperatures through regulated reduction in fertility might be beneficial for plant fitness. Support for this hypothesis comes from the specific decrease in auxin levels in anthers upon heat, while in vegetative tissues it increases (Du et al. 2013; Sakata et al. 2010). Insight into the molecular regulation of the two contrasting responses might shed light on this. Secondly, it could be hypothesized that under stress conditions, it could be advantageous to keep the female gametophyte and kill the male gametes. This would promote outcrossing and thus result in higher genetic variability among offspring, which could increase the chance of genetic adaption to adverse conditions. This idea fits 
with the finding that plants under stress conditions, including heat, show higher homologous recombination frequency (Boyko et al. 2010).

For the future, obtaining knowledge on the genetic basis of (natural) variation in pollen thermotolerance, by applying a forward genetic approach, which has been highly fruitful in many areas of plant research, may be necessary to really get a grip on this aspect of plant biology. Further challenges lie in understanding the similarity in problems caused by and responses to other abiotic stresses, such as drought and high salinity, which also affect male gametophyte development (Storme and Geelen 2013). The common co-occurrence of these stress factors in natural situations argues for studying how they interact.

Author contribution statement F.M. and I.R. wrote the manuscript. All authors read and approved the manuscript.

Acknowledgments This work was supported by the European Commission (Marie Curie Initial Training Network FP7: Solanaceae Pollen Thermotolarance/SPOT-ITN, Grant No. 289220).

Open Access This article is distributed under the terms of the Creative Commons Attribution 4.0 International License (http://crea tivecommons.org/licenses/by/4.0/), which permits unrestricted use, distribution, and reproduction in any medium, provided you give appropriate credit to the original author(s) and the source, provide a link to the Creative Commons license, and indicate if changes were made.

\section{References}

Abiko M et al (2005) High-temperature induction of male sterility during barley (Hordeum vulgare L.) anther development is mediated by transcriptional inhibition. Sex Plant Reprod 18:91-100. doi:10.1007/s00497-005-0004-2

Ahmed FE, Hall AE, DeMason DA (1992) Heat injury during floral development in cowpea (Vigna unguiculata, Fabaceae). Am J Bot 79:784-791

Alfonso M, Yruela I, Almarcegui S, Torrado E, Perez MA, Picorel R (2001) Unusual tolerance to high temperatures in a new herbicide-resistant D1 mutant from Glycine $\max (\mathrm{L}$.) Merr. cell cultures deficient in fatty acid desaturation. Planta 212:573-582. doi: $10.1007 / \mathrm{s} 004250000421$

Alghabari F, Lukac M, Jones HE, Gooding MJ (2014) Effect of Rht alleles on the tolerance of wheat grain set to high temperature and drought stress during booting and anthesis. J Agron Crop Sci 200:36-45. doi:10.1111/jac.12038

Almeselmani M, Deshmukh PS, Sairam RK, Kushwaha SR, Singh TP (2006) Protective role of antioxidant enzymes under high temperature stress. Plant Sci 171:382-388. doi:10.1016/j. plantsci.2006.04.009

Aloni B, Peet M, Pharr M, Karni L (2001) The effect of high temperature and high atmospheric $\mathrm{CO}_{2}$ on carbohydrate changes in bell pepper (Capsicum annuum) pollen in relation to its germination. Physiol Plant 112:505-512

Atkin OK, Tjoelker MG (2003) Thermal acclimation and the dynamic response of plant respiration to temperature. Trends Plant Sci 8:343-351. doi:10.1016/S1360-1385(03)00136-5

Aya K, Ueguchi-Tanaka M, Kondo M, Hamada K, Yano K, Nishimura M, Matsuoka M (2009) Gibberellin modulates anther development in rice via the transcriptional regulation of GAMYB. Plant Cell 21:1453-1472. doi:10.1105/tpc.108.062935

Bac-Molenaar JA, Fradin EF, Becker FF, Rienstra JA, van der Schoot J, Vreugdenhil D, Keurentjes JJ (2015) Genome-wide association mapping of fertility reduction upon heat stress reveals developmental stage-specific QTLs in Arabidopsis thaliana. Plant Cell 27:1857-1874. doi:10.1105/tpc.15.00248

Balogh $G$ et al (2013) Key role of lipids in heat stress management. FEBS Lett 587:1970-1980. doi:10.1016/j.febs let.2013.05.016

Baron KN, Schroeder DF, Stasolla C (2012) Transcriptional response of abscisic acid (ABA) metabolism and transport to cold and heat stress applied at the reproductive stage of development in Arabidopsis thaliana. Plant Sci 188:48-59. doi:10.1016/j. plantsci.2012.03.001

Becker JD, Boavida LC, Carneiro J, Haury M, Feijo JA (2003) Transcriptional profiling of Arabidopsis tissues reveals the unique characteristics of the pollen transcriptome. Plant Physiol 133:713-725. doi:10.1104/pp.103.028241

Bhattacharjee S (2013) Heat and chilling induced disruption of redox homeostasis and its regulation by hydrogen peroxide in germinating rice seeds (Oryza sativa L., cultivar Ratna). Physiol Mol Biol Plants 19:199-207. doi:10.1007/s12298-012-0159-x

Bita CE, Zenoni S, Vriezen WH, Mariani C, Pezzotti M, Gerats T (2011) Temperature stress differentially modulates transcription in meiotic anthers of heat-tolerant and heat-sensitive tomato plants. BMC Genom 12:384. doi:10.1186/1471-2164-12-384

Bokszczanin KL, Fragkostefanakis S, Thermotolerance SP (2013) Perspectives on deciphering mechanisms underlying plant heat stress response and thermotolerance. Front Plant Sci 4:315. doi:10.3389/Fpls.2013.00315

Borg M, Brownfield L, Twell D (2009) Male gametophyte development: a molecular perspective. J Exp Bot 60:1465-1478. doi:10. 1093/jxb/ern355

Boyko A, Filkowski J, Kovalchuk I (2005) Homologous recombination in plants is temperature and day-length dependent. Mutat Res 572:73-83. doi:10.1016/j.mrfmmm.2004.12.011

Boyko A et al (2010) Transgenerational adaptation of arabidopsis to stress requires DNA methylation and the function of dicer-like proteins. PLoS ONE 5:e9514. doi:10.1371/journal.pone.0009514

Burke JJ, Chen JP (2015) Enhancement of reproductive heat tolerance in plants. PLoS ONE 10:e0122933. doi:10.1371/journal.pone. 0122933

Chan-Schaminet KY, Baniwal SK, Bublak D, Nover L, Scharf KD (2009) Specific interaction between tomato HsfA1 and HsfA2 creates hetero-oligomeric superactivator complexes for synergistic activation of heat stress gene expression. J Biol Chem 284:20848-20857. doi:10.1074/jbc.M109.007336

Chao YY, Hsu YT, Kao CH (2009) Involvement of glutathione in heat shock- and hydrogen peroxide-induced cadmium tolerance of rice (Oryza sativa L.) seedlings. Plant Soil 318:37-45. doi:10. 1007/s11104-008-9815-X

Charng YY, Liu HC, Liu NY, Chi WT, Wang CN, Chang SH, Wang TT (2007) A heat-inducible transcription factor, HsfA2, is required for extension of acquired thermotolerance in Arabidopsis. Plant Physiol 143:251-262. doi:10.1104/pp.106. 091322

Chaturvedi P, Ischebeck T, Egelhofer V, Lichtscheidl I, Weckwerth W (2013) Cell-specific analysis of the tomato pollen proteome from pollen mother cell to mature pollen provides evidence for developmental priming. J Proteome Res 12:4892-4903. doi:10. $1021 / \mathrm{pr} 400197 \mathrm{p}$

Chaturvedi $\mathrm{P}$ et al (2015) Heat-treatment-responsive proteins in different developmental stages of tomato pollen detected by targeted mass accuracy precursor alignment (tMAPA). J Proteome Res 14:4463-4471. doi:10.1021/pr501240n 
Che P, Bussell JD, Zhou WX, Estavillo GM, Pogson BJ, Smith SM (2010) Signaling from the endoplasmic reticulum activates brassinosteroid signaling and promotes acclimation to stress in Arabidopsis. Sci Signal 3:ra69. doi:10.1126/scisignal.2001140

Chen SC et al (2013) Overexpression of mitochondrial uncoupling protein conferred resistance to heat stress and Botrytis cinerea infection in tomato. Plant Physiol Bioch 73:245-253. doi:10. 1016/j.plaphy.2013.10.002

Chhun $\mathrm{T}$ et al (2007) Gibberellin regulates pollen viability and pollen tube growth in rice. Plant Cell 19:3876-3888. doi:10.1105/tpc. 107.054759

Chung P, Hsiao HH, Chen HJ, Chang CW, Wang SJ (2014) Influence of temperature on the expression of the rice sucrose transporter 4 gene, OsSUT4, in germinating embryos and maturing pollen. Acta Physiol Plant 36:217-229. doi:10.1007/s11738-013-1403-x

Coberly LC, Rausher MD (2003) Analysis of a chalcone synthase mutant in Ipomoea purpurea reveals a novel function for flavonoids: amelioration of heat stress. Mol Ecol 12:1113-1124. doi:10.1046/j.1365-294X.2003.01786.x

Cooper P, Ho THD, Hauptmann RM (1984) Tissue-specificity of the heat-shock response in maize. Plant Physiol 75:431-441. doi:10. 1104/Pp.75.2.431

Crone D, Rueda J, Martin KL, Hamilton DA, Mascarenhas JP (2001) The differential expression of a heat shock promoter in floral and reproductive tissues. Plant, Cell Environ 24:869-874. doi:10. 1046/j.1365-3040.2001.00727.x

Davidson RM et al (2011) Utility of RNA sequencing for analysis of maize reproductive transcriptomes. Plant Genome 4:191-203. doi:10.3835/plantgenome2011.05.0015

De Storme N, Geelen D (2014) The impact of environmental stress on male reproductive development in plants: biological processes and molecular mechanisms. Plant, Cell Environ 37:1-18. doi:10. $1111 /$ pce. 12142

Derksen J, van Wezel R, Knuiman B, Ylstra B, van Tunen AJ (1999) Pollen tubes of flavonol-deficient Petunia show striking alterations in wall structure leading to tube disruption. Planta 207:575-581. doi:10.1007/s004250050520

Doukhanina EV, Chen S, van der Zalm E, Godzik A, Reed J, Dickman MB (2006) Identification and functional characterization of the BAG protein family in Arabidopsis thaliana. J Biol Chem 281:18793-18801. doi:10.1074/jbc.M511794200

Du H, Liu HB, Xiong LZ (2013) Endogenous auxin and jasmonic acid levels are differentially modulated by abiotic stresses in rice. Front Plant Sci 4:397. doi:10.3389/Fpls.2013.00397

Dupuis I, Dumas C (1990) Influence of temperature stress on invitro fertilization and heat-shock protein-synthesis in maize (Zea mays L.) reproductive tissues. Plant Physiol 94:665-670. doi:10.1104/ Pp.94.2.665

Endo $\mathrm{M}$ et al (2009) High temperatures cause male sterility in rice plants with transcriptional alterations during pollen development. Plant Cell Physiol 50:1911-1922. doi:10.1093/pcp/pcp135

Firon $\mathrm{N}$ et al (2006) Pollen grains of heat tolerant tomato cultivars retain higher carbohydrate concentration under heat stress conditions. Sci Hortic 109:212-217. doi:10.1016/j.scienta.2006.03.007

Firon N, Pressman E, Meir S, Khoury R, Altahan L (2012) Ethylene is involved in maintaining tomato (Solanum lycopersicum) pollen quality under heat-stress conditions. AoB Plants. doi:10.1093/ aobpla/pls024

Foyer CH, Noctor G (2005) Redox homeostasis and antioxidant signaling: a metabolic interface between stress perception and physiological responses. Plant Cell 17:1866-1875. doi:10.1105/ tpc. 105.033589

Fragkostefanakis S, Simm S, Paul P, Bublak D, Scharf KD, Schleiff E (2015) Chaperone network composition in Solanum lycopersicum explored by transcriptome profiling and microarray metaanalysis. Plant Cell Environ 38:693-709. doi:10.1111/pce.12426
Fragkostefanakis S et al (2016) HsfA2 controls the activity of developmentally and stress-regulated heat stress protection mechanisms in tomato male reproductive tissues. Plant Physiol. doi:10.1104/pp.15.01913

Francis KE, Lam SY, Harrison BD, Bey AL, Berchowitz LE, Copenhaver GP (2007) Pollen tetrad-based visual assay for meiotic recombination in Arabidopsis. Proc Natl Acad Sci USA 104:3913-3918. doi:10.1073/pnas.0608936104

Frank G et al (2009) Transcriptional profiling of maturing tomato (Solanum lycopersicum L.) microspores reveals the involvement of heat shock proteins, ROS scavengers, hormones, and sugars in the heat stress response. J Exp Bot 60:3891-3908. doi:10.1093/ jxb/erp234

Frova C, Taramino G, Binelli G (1989) Heat-shock proteins during pollen development in maize. Dev Genet 10:324-332. doi:10. 1002/dvg. 1020100408

Fujikawa Y et al (2016) Mouse redox histology using genetically encoded probes. Sci Signal 9:rs1. doi:10.1126/scisignal.aad3895

Gagliardi D, Breton C, Chaboud A, Vergne P, Dumas C (1995) Expression of heat shock factor and heat shock protein 70 genes during maize pollen development. Plant Mol Biol 29:841-856. doi:10.1007/Bf00041173

Giorno F, Wolters-Arts M, Grillo S, Scharf KD, Vriezen WH, Mariani C (2010) Developmental and heat stress-regulated expression of HsfA2 and small heat shock proteins in tomato anthers. J Exp Bot 61:453-462. doi:10.1093/jxb/erp316

Guan QM, Lu XY, Zeng HT, Zhang YY, Zhu JH (2013) Heat stress induction of miR398 triggers a regulatory loop that is critical for thermotolerance in Arabidopsis. Plant J 74:840-851. doi:10. 1111/tpj.12169

Haerizadeh F, Wong CE, Bhalla PL, Gresshoff PM, Singh MB (2009) Genomic expression profiling of mature soybean (Glycine max) pollen. BMC Plant Biol 9:25. doi:10.1186/1471-2229-9-25

Hahn A, Bublak D, Schleiff E, Scharf KD (2011) Crosstalk between Hsp90 and Hsp70 chaperones and heat stress transcription factors in tomato. Plant Cell 23:741-755. doi:10.1105/tpc.110. 076018

Harsant J, Pavlovic L, Chiu G, Sultmanis S, Sage TL (2013) High temperature stress and its effect on pollen development and morphological components of harvest index in the $\mathrm{C} 3$ model grass Brachypodium distachyon. J Exp Bot 64:2971-2983. doi:10.1093/jxb/ert142

Hartl FU, Bracher A, Hayer-Hartl M (2011) Molecular chaperones in protein folding and proteostasis. Nature 475:324-332. doi:10. 1038/nature 10317

Higashitani A (2013) High temperature injury and auxin biosynthesis in microsporogenesis. Front Plant Sci 4:47. doi:10.3389/fpls. 2013.00047

Holford P, Croft J, Newbury HJ (1991) Structural studies of microsporogenesis in fertile and male-sterile onions (Allium Cepa L.) containing the Cms-S cytoplasm. Theor Appl Genet 82:745-755

Hong SW, Vierling E (2000) Mutants of Arabidopsis thaliana defective in the acquisition of tolerance to high temperature stress. Proc Natl Acad Sci USA 97:4392-4397. doi:10.1073/ pnas.97.8.4392

Hopf N, Plesofskyvig N, Brambl R (1992) The heat-shock response of pollen and other tissues of maize. Plant Mol Biol 19:623-630. doi:10.1007/Bf00026788

$\mathrm{Hu} \mathrm{J}$ et al (2014) Mitochondria and cytoplasmic male sterility in plants. Mitochondrion 19:282-288. doi:10.1016/j.mito.2014.02.008

IPCC (2014) Climate change 2014: impacts, adaptation, and vulnerability. Part A: global and sectoral aspects. Contribution of working group II to the fifth assessment report of the Intergovernmental Panel on Climate Change. Cambridge University Press, Cambridge 
Iwahori S (1965) High temperature injuries in tomato. IV. Development of normal flower buds and morphological abnormalities of flower buds treated with high temperature. J Jpn Soc Hortic Sci 34:33-41

Jacobsen SE, Olszewski NE (1991) Characterization of the arrest in anther development associated with gibberellin deficiency of the Gib-1 mutant of tomato. Plant Physiol 97:409-414. doi:10.1104/ Pp.97.1.409

Ji X et al (2011) Control of abscisic acid catabolism and abscisic acid homeostasis is important for reproductive stage stress tolerance in cereals. Plant Physiol 156:647-662. doi:10.1104/pp.111. 176164

Karni L, Aloni B (2002) Fructokinase and hexokinase from pollen grains of bell pepper (Capsicum annuиm L.): possible role in pollen germination under conditions of high temperature and $\mathrm{CO}_{2}$ enrichment. Ann Bot Lond 90:607-612. doi:10.1093/aob/ $\operatorname{mcf} 234$

Kaur R, Bains TS, Bindumadhava H, Nayyar H (2015) Responses of mungbean (Vigna radiata L.) genotypes to heat stress: effects on reproductive biology, leaf function and yield traits. Sci Hortic Amst 197:527-541. doi:10.1016/j.scienta.2015.10.015

Kim SY, Hong CB, Lee I (2001) Heat shock stress causes stagespecific male sterility in Arabidopsis thaliana. J Plant Res 114:301-307

Koornneef M, van der Veen JH (1980) Induction and analysis of gibberellin sensitive mutants in Arabidopsis thaliana (L.) heynh. Theor Appl Genet 58:257-263. doi:10.1007/BF00265176

Kotak S, Larkindale J, Lee U, von Koskull-Doring P, Vierling E, Scharf $\mathrm{KD}$ (2007) Complexity of the heat stress response in plants. Curr Opin Plant Biol 10:310-316. doi:10.1016/j.pbi.2007.04.011

Kumar SV, Wigge PA (2010) H2A.Z-containing nucleosomes mediate the thermosensory response in Arabidopsis. Cell 140:136-147. doi:10.1016/j.cell.2009.11.006

Kumar RR et al (2014) Ascorbic acid at pre-anthesis modulate the thermotolerance level of wheat (Triticum aestivum) pollen under heat stress. J Plant Biochem Biotechnol 23:293-306. doi:10. 1007/s13562-013-0214-x

Lamke J, Brzezinka K, Altmann S, Baurle I (2015) A hit-and-run heat shock factor governs sustained histone methylation and transcriptional stress memory. EMBO J. doi:10.15252/embj. 201592593

Larkindale J, Huang BR (2005) Effects of abscisic acid, salicylic acid, ethylene and hydrogen peroxide in thermotolerance and recovery for creeping bentgrass. Plant Growth Regul 47:17-28. doi:10. 1007/s10725-005-1536-z

Larkindale J, Vierling E (2008) Core genome responses involved in acclimation to high temperature. Plant Physiol 146:748-761. doi:10.1104/pp.107.112060

Lebel EG, Masson J, Bogucki A, Paszkowski J (1993) Stress-induced intrachromosomal recombination in plant somatic-cells. Proc Natl Acad Sci USA 90:422-426. doi:10.1073/pnas.90.2.422

Lee SLJ, Warmke HE (1979) Organelle size and number in fertile and T-cytoplasmic male-sterile corn. Am J Bot 66:141-148. doi:10. $2307 / 2442516$

Liu LW, Huang H, Gong YQ, Chen CS, Wang LZ (2009) Cytological and ultra-structural study on microsporogenesis of cytoplasmic male sterility in Raphanus sativus. Biologia 64:716-722. doi:10. 2478/s11756-009-0063-1

Liu HC, Liao HT, Charng YY (2011) The role of class A1 heat shock factors (HSFA1s) in response to heat and other stresses in Arabidopsis. Plant, Cell Environ 34:738-751. doi:10.1111/j. 1365-3040.2011.02278.x

Meyer AJ, Brach T, Marty L, Kreye S, Rouhier N, Jacquot JP, Hell R (2007) Redox-sensitive GFP in Arabidopsis thaliana is a quantitative biosensor for the redox potential of the cellular glutathione redox buffer. Plant J 52:973-986. doi:10.1111/j. 1365-313X.2007.03280.x

Mishra SK, Tripp J, Winkelhaus S, Tschiersch B, Theres K, Nover L, Scharf KD (2002) In the complex family of heat stress transcription factors, HSfA1 has a unique role as master regulator of thermotolerance in tomato. Gene Dev 16:1555-1567. doi:10.1101/gad.228802

Mittal D, Madhyastha DA, Grover A (2012) Genome-wide transcriptional profiles during temperature and oxidative stress reveal coordinated expression patterns and overlapping regulons in rice. PLoS ONE 7:e40899. doi:10.1371/journal.pone.0040899

Mittler R, Finka A, Goloubinoff P (2012) How do plants feel the heat? Trends Biochem Sci 37:118-125. doi:10.1016/j.tibs.2011.11.007

Moreno AA, Orellana A (2011) The physiological role of the unfolded protein response in plants. Biol Res 44:75-80

Mulholland BJ, Edmondson RN, Fussell M, Basham J, Ho LC (2003) Effects of high temperature on tomato summer fruit quality. J Hortic Sci Biotech 78:365-374

Muller J, Menzel D, Samaj J (2007) Cell-type-specific disruption and recovery of the cytoskeleton in Arabidopsis thaliana epidermal root cells upon heat shock stress. Protoplasma 230:231-242. doi:10.1007/s00709-006-0239-2

Munoz-Bertomeu J et al (2010) The plastidial glyceraldehyde-3phosphate dehydrogenase is critical for viable pollen development in Arabidopsis. Plant Physiol 152:1830-1841. doi:10.1104/ pp. 109.150458

Omidi M, Siahpoosh MR, Mamghani R, Modarresi M (2014) The influence of terminal heat stress on meiosis abnormalities in pollen mother cells of wheat. Cytologia 79:49-58. doi:10.1508/ cytologia.79.49

Oshino T, Abiko M, Saito R, Ichiishi E, Endo M, KawagishiKobayashi M, Higashitani A (2007) Premature progression of anther early developmental programs accompanied by comprehensive alterations in transcription during high-temperature injury in barley plants. Mol Genet Genomics 278:31-42. doi:10.1007/s00438-007-0229-x

Parish RW, Phan HA, Iacuone S, Li SF (2012) Tapetal development and abiotic stress: a centre of vulnerability. Funct Plant Biol 39:553-559. doi:10.1071/FP12090

Parish RW, Phan HA, Iacuone S, Li SF (2013) Tapetal development and abiotic stress: a centre of vulnerability 39:553-559. doi:10. 1071/fp12090

Parrotta L, Faleri C, Cresti M, Cai G (2016) Heat stress affects the cytoskeleton and the delivery of sucrose synthase in tobacco pollen tubes. Planta 243:43-63. doi:10.1007/s00425015-2394-1

Pecrix Y, Rallo G, Folzer H, Cigna M, Gudin S, Le Bris M (2011) Polyploidization mechanisms: temperature environment can induce diploid gamete formation in Rosa sp. J Exp Bot 62:3587-3597. doi:10.1093/jxb/err052

Pressman E, Peet MM, Pharr DM (2002) The effect of heat stress on tomato pollen characteristics is associated with changes in carbohydrates concentration in the developing anthers. Ann Bot 2002:631-636

Pressman E, Harel D, Zamski E, Shaked R, Althan L, Rosenfeld K, Firon N (2006) The effect of high temperatures on the expression and activity of sucrose-cleaving enzymes during tomato ( $L y$ copersicon esculentum) anther development. J Hortic Sci Biotech 81:341-348

Qin DD et al (2008) Heat stress-responsive transcriptome analysis in heat susceptible and tolerant wheat (Triticum aestivum L.) by using wheat genome array. BMC Genom 9:432. doi:10.1186/ 1471-2164-9-432

Renak D, Gibalova A, Solcova K, Honys D (2014) A new link between stress response and nucleolar function during pollen 
development in Arabidopsis mediated by AtREN1 protein. Plant, Cell Environ 37:670-683. doi:10.1111/pce.12186

Rezaei M, Arzani A, Sayed-Tabatabaei BE (2010) Meiotic behaviour of tetraploid wheats (Triticum turgidum L.) and their synthetic hexaploid wheat derivates influenced by meiotic restitution and heat stress. J Genet 89:401-407

Rui R, Nie Y, Tong H (1990) SOD activity as a parameter for screening stress-tolerant germplasm resources in sweet potato (Ipomoea batatas L.). Jiangsu J Agric Sci 6:52-56

Saini HS, Sedgley M, Aspinall D (1984) Developmental anatomy in wheat of male-sterility induced by heat-stress, water deficit or abscisic-acid. Aust J Plant Physiol 11:243-253

Sairam RK, Srivastava GC, Saxena DC (2000) Increased antioxidant activity under elevated temperatures: a mechanism of heat stress tolerance in wheat genotypes. Biol Plantarum 43:245-251. doi:10.1023/A:1002756311146

Sakata T et al (2010) Auxins reverse plant male sterility caused by high temperatures. Proc Natl Acad Sci USA 107:8569-8574. doi:10.1073/pnas.1000869107

Sangwan V, Orvar BL, Beyerly J, Hirt H, Dhindsa RS (2002) Opposite changes in membrane fluidity mimic cold and heat stress activation of distinct plant MAP kinase pathways. Plant J 31:629-638. doi:10.1046/j.1365-313X.2002.01384.x

Sato S, Peet MM, Thomas JF (2002) Determining critical pre- and post-anthesis periods and physiological processes in Lycopersicon esculentum Mill. exposed to moderately elevated temperatures. J Exp Bot 53:1187-1195. doi:10.1093/jexbot/53.371.1187

Scharf KD, Berberich T, Ebersberger I, Nover L (2012) The plant heat stress transcription factor (Hsf) family: structure, function and evolution. Bba-Gene Regul Mech 1819:104-119. doi:10. 1016/j.bbagrm.2011.10.002

Schijlen EGWM et al (2007) RNA interference silencing of Chalcone synthase, the first step in the flavonoid biosynthesis pathway, leads to parthenocarpic tomato fruits. Plant Physiol 144:1520-1530. doi:10.1104/pp.107.100305

Schnable PS, Wise RP (1998) The molecular basis of cytoplasmic male sterility and fertility restoration. Trends Plant Sci 3:175-180. doi:10.1016/S1360-1385(98)01235-7

Schramm F, Ganguli A, Kiehlmann E, Englich G, Walch D, von Koskull-Doring P (2006) The heat stress transcription factor HsfA2 serves as a regulatory amplifier of a subset of genes in the heat stress response in Arabidopsis. Plant Mol Biol 60:759-772. doi: $10.1007 / \mathrm{s} 11103-005-5750-\mathrm{x}$

Selinski J, Scheibe R (2014) Pollen tube growth: where does the energy come from? Plant Signal Behav 9:e977200. doi:10.4161/ 15592324.2014.977200

Sengupta A, Webb RP, Holaday AS, Allen RD (1993) Overexpression of superoxide-dismutase protects plants from oxidative stress-induction of ascorbate peroxidase in superoxide dismutase-overexpressing plants. Plant Physiol 103:1067-1073

Sharma P, Jha AB, Dubey RS, Pessarakli M (2012) Reactive oxygen species, oxidative damage, and antioxidative defense mechanism in plants under stressful conditions. J Bot 2012:26. doi:10.1155/ 2012/217037

Smertenko A, Draber P, Viklicky V, Opatrny Z (1997) Heat stress affects the organization of microtubules and cell division in Nicotiana tabacum cells. Plant, Cell Environ 20:1534-1542. doi:10.1046/j.1365-3040.1997.d01-44.x

Smith MB, Palmer RG, Horner HT (2002) Microscopy of a cytoplasmic male-sterile soybean from an interspecific cross between Glycine max and G-soja (leguminosae). Am J Bot 89:417-426. doi:10.3732/Ajb.89.3.417

Storme ND, Geelen D (2013) The impact of environmental stress on male reproductive development in plants: biological processes and molecular mechanisms. doi:10.1111/pce.12142
Suzuki K, Takeda H, Tsukaguchi T, Egawa Y (2001) Ultrastructural study on degeneration of tapetum in anther of snap bean (Phaseolus vulgaris L.) under heat stress. Sex Plant Reprod 13:293-299

Tang R-S, Zheng J-C, Jin Z-Q, Zhang D-D, Huang Y-H, Chen L-G (2008) Possible correlation between high temperature-induced floret sterility and endogenous levels of IAA, GAs and ABA in rice (Oryza sativa L.). Plant Growth Regul 54:37-43. doi:10. 1007/s10725-007-9225-8

Tsuji $\mathrm{H}$ et al (2006) GAMYB controls different sets of genes and is differentially regulated by microRNA in aleurone cells and anthers. Plant J 47:427-444. doi:10.1111/j.1365-313X.2006. 02795. $\mathrm{x}$

Tsvetkova NM et al (2002) Small heat-shock proteins regulate membrane lipid polymorphism. Proc Natl Acad Sci USA 99:13504-13509. doi:10.1073/pnas.192468399

Tunc-Ozdemir M et al (2013) A cyclic nucleotide-gated channel (CNGC16) in pollen is critical for stress tolerance in pollen reproductive development. Plant Physiol 161:1010-1020. doi:10. 1104/pp.112.206888

Vacca RA, de Pinto MC, Valenti D, Passarella S, Marra E, De Gara L (2004) Production of reactive oxygen species, alteration of cytosolic ascorbate peroxidase, and impairment of mitochondrial metabolism are early events in heat shock-induced programmed cell death in tobacco bright-yellow 2 cells. Plant Physiol 134:1100-1112. doi:10.1104/pp.103.035956

Vierling E (1991) The roles of heat-shock proteins in plants. Annu Rev Plant Phys 42:579-620. doi:10.1146/annurev.arplant.42.1. 579

Volkov RA, Panchuk II, Schoffl F (2005) Small heat shock proteins are differentially regulated during pollen development and following heat stress in tobacco. Plant Mol Biol 57:487-502. doi:10.1007/s11103-005-0339-y

von Koskull-Doring P, Scharf KD, Nover L (2007) The diversity of plant heat stress transcription factors. Trends Plant Sci 12:452-457. doi:10.1016/j.tplants.2007.08.014

Wahid A, Gelani S, Ashraf M, Foolad M (2007) Heat tolerance in plants: an overview. Environ Exp Bot 61:199-223. doi:10.1016/ j.envexpbot.2007.05.011

Wang X, Cai JA, Jiang D, Liu FL, Dai TB, Cao WX (2011) Preanthesis high-temperature acclimation alleviates damage to the flag leaf caused by post-anthesis heat stress in wheat. J Plant Physiol 168:585-593. doi:10.1016/j.jplph.2010.09.016

Wang $X$ et al (2012) Pre-anthesis high temperature acclimation alleviates the negative effects of post-anthesis heat stress on stem stored carbohydrates remobilization and grain starch accumulation in wheat. J Cereal Sci 55:331-336. doi:10.1016/j.jcs.2012. 01.004

Whittle CA, Otto SP, Johnston MO, Krochko JE (2009) Adaptive epigenetic memory of ancestral temperature regime in Arabidopsis thaliana. Botany 87:650-657. doi:10.1139/B09-030

Wu QY et al (2012) Ectopic expression of Arabidopsis glutaredoxin AtGRXS17 enhances thermotolerance in tomato. Plant Biotechnol J 10:945-955. doi:10.1111/j.1467-7652.2012.00723.x

Yang JY, Sun Y, Sun AQ, Yi SY, Qin J, Li MH, Liu J (2006) The involvement of chloroplast HSP100/ClpB in the acquired thermotolerance in tomato. Plant Mol Biol 62:385-395. doi:10. 1007/s11103-006-9027-9

Zhang XW et al (2014) Microarray data uncover the genome-wide gene expression patterns in response to heat stress in rice postmeiosis panicle. J Plant Biol 57:327-336. doi:10.1007/s12374014-0177-z

Zinn KE, Tunc-Ozdemir M, Harper JF (2010) Temperature stress and plant sexual reproduction: uncovering the weakest links. J Exp Bot 61:1959-1968. doi:10.1093/Jxb/Erq053 